\title{
Reviews
}

\section{Scaling Methods of Sediment Bioremediation Processes and Applications}

\author{
By P. Adriaens*, M.-Y. Li, and A. M. Michalak
}

\author{
DOI: $10.1002 / \mathrm{elsc} .200520127$
}

Bioremediation has been argued to be one of the most cost-effective remediation technologies available to reduce soil, sediment, or groundwater contamination, particularly because this approach may allow for the implementation of in-place strategies. Recent trends have advocated the application of innovative sediment stabilization strategies through placement of (reactive) capping material to allow long-term biodegradation of contaminants in these complex biogeochemical environments. The potential long-term risk reduction associated with this approach requires a demonstration of causal relationships between sediment or contaminant stability on the one hand, and microbial reactivity on the other. The spatial analysis needed to fully understand and quantify these correlations requires sensitive probabilistic techniques. Geostatistics has been used for the characterization of multi-scale spatial patterns for the last few decades, and the analysis of microbial attributes has shown significant spatial structures on microbial abundance and activity. However, there is a dearth of information on the applicability of geostatistics to quantitatively describe the interaction between the microorganisms and their environment. Using the Passaic River (NJ) dioxin data as a model dataset, multiple scaling models were applied to scale and interpolate sampled dioxin data and derive dechlorination signatures in sediments. Unlike conventional geostatistic tools that are based on the pointto-point spatial structures, the new multi-scale model (M-Scale) introduces a new framework for spatial analysis in which regional values at different scales are anchored by the correlations to each other. Spatial dioxin distributions and microbial dechlorination signatures were used as benchmarks for comparison of M-Scale to ordinary kriging. The results from cross-validation and jackknifing approaches applied to these datasets were analyzed and compared using Quantile-Quantile (Q-Q) plots and reproduction coefficients. These plots indicated that the M-Scale better preserves the local features of hotspots during data interpolation to a basin-wide scale. Current efforts focus on mapping microbial abundance and respiratory competence in the Anacostia River, based on measurements at three different scales. The outcomes of this work will be used to develop an uncertainty-based spatial decision tool for site remediation in this watershed using various capping strategies.

\section{Introduction}

Sediment remediation is a challenging problem from a site characterization, remedial design implementation and remedial endpoint assessment perspective, due to the complexity inherent in aquatic environments. Remediation strategies are often developed on the basis of insufficient understanding of fundamental processes and site-specific empirical models, which have to be recreated at each site. High uncertainties can lead to estimates of risks that are too conservative, adding to remediation costs, or they can lead to insufficient protection, resulting in unanticipated impacts on human health and ecology.

The current available in-place sediment remediation strategies are limited to dredging followed by disposal in submerged or partially saturated $(60 \%)$ confined disposal

[*] P. Adriaens (author to whom correspondence should be addressed, e-mail: adriaens@umich.edu), M.-Y. Li, A. M. Michalak, The University of Michigan, Department of Civil and Environmental Engineering, 1351 Beal Ave, 175 EWRE Bldg, Ann Arbor, MI 48109-2125, USA. facilities (CFDs), in situ capping approaches using either inert or reactive barriers, contained aquatic disposal (CAD), or natural recovery (see Fig. 1). The first approach has become unsustainable, for political and social reasons, as well due to the problems associated with difficult-to-quantify contaminant transport pathways. Moreover, in situ CAD is less attractive as it still requires dredging prior to disposal. The alternative approaches have received increased attention as contaminated site management options. Their application has been limited due to the uncertainties about long-term stability and exposure pathways under various environmental conditions.

The critical processes affecting contaminants in sediments are bioturbation, erosion/resuspension, diffusion, advection, biogeochemical interactions and biotic or abiotic transformation reactions [1], as illustrated in Fig. 2. This figure represents an abstraction of a characteristic sediment model, incorporating the sediment bed, a sediment cap (either sand or a reactive matrix) and the overlaying water column. The arrows indicate the direction in which the processes impact the contaminants or contaminant-associated sediments 


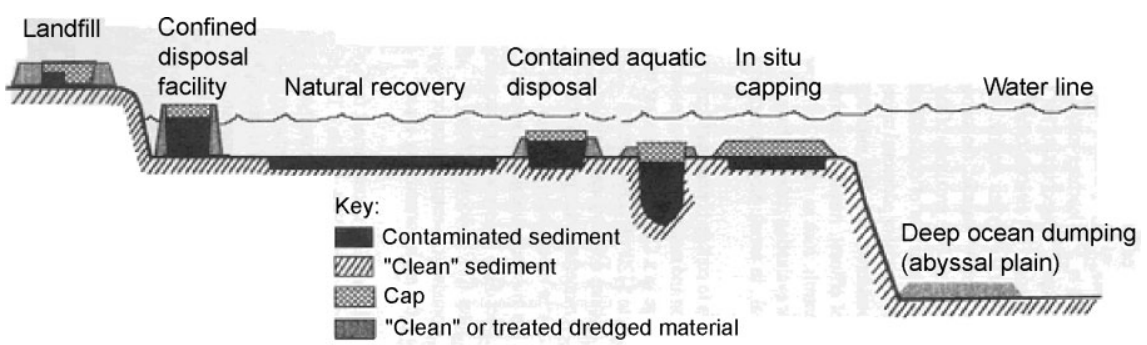

Figure 1. In-place sediment remediation strategies (from NRC, 1997 [1]).

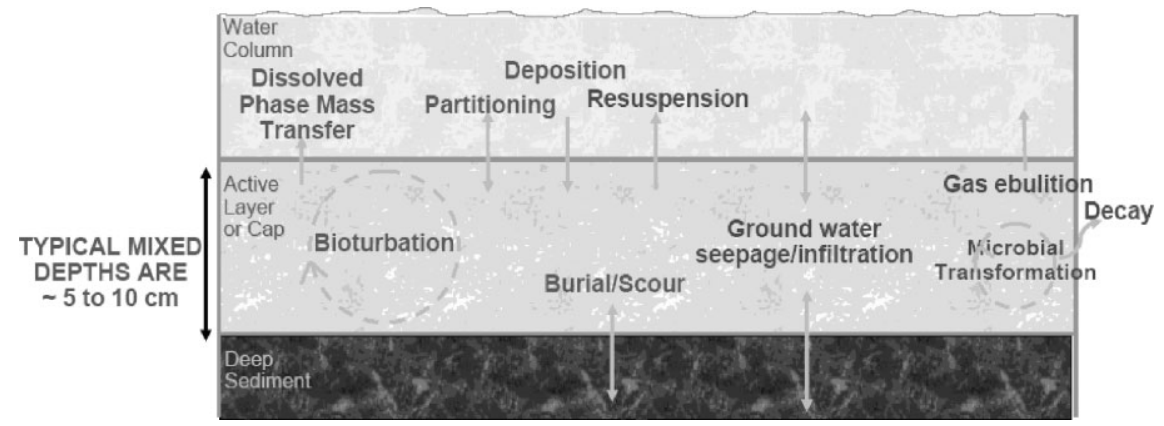

Figure 2. Components of contaminant transport/transformation in sediment beds.

cap design [2,3]. The effect of even low seepage rates must be validated in the laboratory as well as in the field, especially since groundwater fluxes may have effects on biogeochemical processes and redox conditions over time [4].

Erosion rates of fine-grained cohesive sediments are often modeled as a linear function of the applied shear stress above some threshold or critical value [5]. The constant of proportionality varies with a number of system variables, including the environment in which the sediment was deposited [6,7], the $\mathrm{pH}$ of the sediment pore water [8], salinity $[9,10]$, as well as the bulk density of the sediment $[7,10]$. It is generally accepted that the strength of these sediments is controlled by the physical-chemical bonds between the surfacecharged particles. A vertically upward flow of pore fluid, associated

across these compartments, and shows that active mixing in sediments due to biological activity occurs in the top $5-10 \mathrm{~cm}$. Attempts have been made to quantify the order of magnitude of these processes and how they are impacting the overall contaminant fluxes in sediment systems, resulting in rates that range over up to three orders of magnitude.

In addition to the knowledge gaps in the understanding of fundamental principles and information applicable to contaminated sediments in general, there is also a deficit of sitespecific information for characterization of sediment resuspension and biogeochemistry/sediment microbiology. It is thus imperative to develop a better understanding of fundamental processes and to incorporate the uncertainties therewith to assess their impact on remedial technologies, in order to achieve higher cost efficiency and reliable protection. The following sections will provide a brief overview of some of the predominant processes impacting in-place sediment remediation, and the approaches used to evaluate spatial uncertainty of their impact.

\section{Groundwater Advection in Sediments}

The interaction of groundwater with streams and lakes has been extensively studied, yet little is known about the constraints such interaction may impose upon in-situ contaminated sediment remediation. This phenomenon can affect sediments physically by favoring or suppressing resuspension, depending on the direction of water exchange and grain-size. The extent to which groundwater advection affects the chemical and physical stability of contaminants in sediment and under caps is an important factor for sediment with groundwater discharge will induce a mechanical stress that could result in resuspension of fine material [11]. This process would be expected to affect the displacement of fine-grained sediments through a cap material. An additional mechanism of importance in the marine environment is that a fresh groundwater discharge could reduce the ionic concentration of the pore fluids and reduce the strength of the interparticle forces. Pore water seepage could also reduce the consolidation rates in the sediment, decreasing the bulk density as well as the erosion resistance.

\section{Sediment Biogeochemistry}

Microbial activities can impact contaminant mobility in both positive and negative ways [12], by influencing chemical sorption, by causing ebullition of gases [13], and by chemically altering the contaminants themselves $[14,15]$. Chemical transformations can lead to less toxic or more toxic compounds, depending on the contaminant and on the predominant pathways. Ebullition of biogenic gases resulting from microbial metabolism (e.g., methane, hydrogen sulfide, carbon dioxide) can destabilize the sediment or cap matrix, and induce desorption of organic contaminants from the sediment particles into the (organic) gas, thus facilitating convective and diffusive transport [16]. Biogeochemical cycling is thus an important component to be considered for the long-term performance of in-situ sediment remediation technologies.

Because of the high sulfate concentrations in saline environments, sulfate-reduction is often the dominant process in carbon metabolism in marine sediments [17], although fermentation [18], denitrification [19,20], iron reduction [21], and methanogenesis [18] have been demonstrated. These 
conditions are conducive to reduction reactions such as dechlorination of PCBs and dioxins [14], and aromatic ring destabilization of PAHs. Natural dechlorination rates for these compounds range from one chlorine removed every seven to ten years, depending on the rates of carbon turnover in the sediments [22]. Lesser chlorinated compounds have been hypothesized to migrate out of the sediments into the water column or upper sediment layers [23-25].

The formation and migration of biogenic gas in marine sediments, its effect on sediment bed morphology and stability, and emissions into the water column and atmosphere have been well documented [26-28]. It is generally observed that the generation of biochemical gases depends on the amount of organic matter in sediment and on the sediment cover thickness, decreasing seaward [29]. However, limited direct measurements of gas diffusion in porous matrices have been reported, and the available information is generally restricted to methane, carbon dioxide, and oxygen [30,31]. In addition, gases can be transported to the sediments through groundwater and dominate in-situ production [32].

Very little is known about the potential of gases to physically and chemically destabilize either caps or natural sediments. It is known that gas generation is dependent on temperature [33], and that the effects of temperature can be attenuated using thicker and thus more insulating caps, but thorough scientific investigation of the phenomenon is lacking, in particular with respect to contaminated sediment management. The significant uncertainties hinder the development of models that account for sediment/cap stability as a function of outgassing [16].
Deterministic models, derived based on physics laws that are generally accepted, are applied for the simplicity of their formulation or for the ease of explanation to a broader audience. Stochastic models, on the other hand, are often used to measure the uncertainty accompanied with restriction of sample size due to the cost of taking samples even if no physics laws may apply. In addition to the basic use of a stochastic model, the applications may also include the forecasting or estimation of a certain attribute based on previous measurements, or simplification of input/output relationships. Fig. 3 illustrates the uncertainty associated with sample collection, and indicates that, considering the limited number of samples collected, any observation is only known within the context of a probability distribution - i.e., there are many equally-probable realities capturing the observation.

A mixed deterministic and stochastic approach may provide an alternative that evaluates the parameters of a deterministic model from the specific site measurements and leaves out the residuals for stochastic analysis. The mixed approach, however, is usually categorized as a stochastic approach based on the fact the models are taking statistic components into consideration. For example, kriging with a trend model deals with a varying local trend within a certain neighborhood expressed by a deterministic function of the coordinates [35]. The deterministic components of the model require interdisciplinary knowledge from experts in flow modeling and lab experiments, who should be involved in the stochastic estimation in the cases where physical models are available for attribute quantification, and when propor-

\section{Uncertainty Modeling and Decision Making: Deterministic and Stochastic Models for Sediment Remediation}

To assess the dependence of contaminant reduction as a function of site-specific attributes such as advective transport and biogeochemistry, model estimations are usually required, due to the limited number of samples collected. The choice of methods or models to be used, to this end, is the first step in estimation. Unfortunately, the choice is often made on a largely subjective and intuitive basis [34]. While some subjectivity may always be involved, the choice of an estimation method usually depends on consideration of deterministic or stochastic approaches, and whether a particular method and its parameter values are suited to the application.

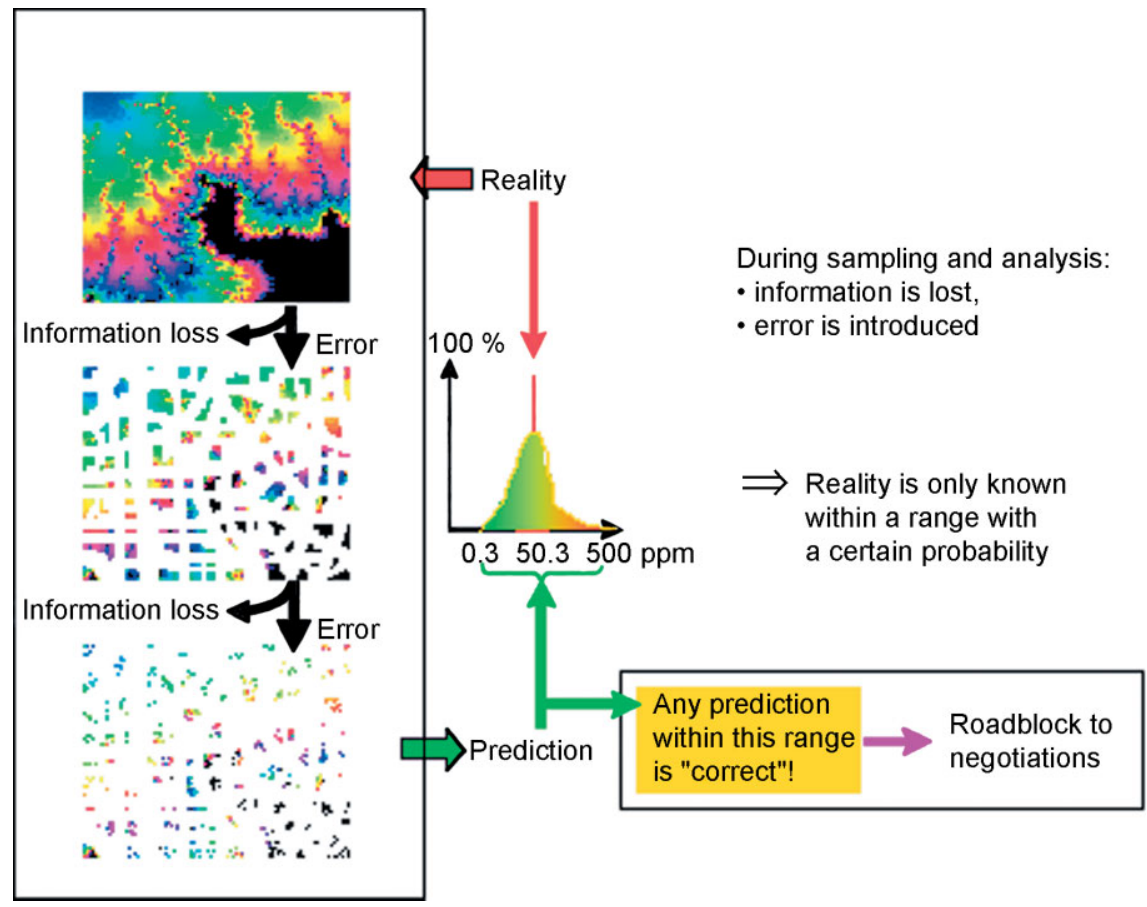

Figure 3. Principles of uncertainty imparted by information loss during point sampling, and the need for probability distribution functions to make uncertainty-based predictions (according to Barabas, 2003 [77]). 
tional effects are identified (i.e., the residual is related to the trend of attributes).

Until now, most of the mathematical models used in predictive microbiology are deterministic, i.e., their outcome is an estimate for the microbial attribute at a certain time instant [36]. For a more advanced analysis of predictive microbiology in the context of hazard analysis and critical control point and risk analysis studies, stochastic models should be developed. Such models predict a probability distribution for the microbial attribute within proper temporal and spatial constraints.

Risk assessment is an integral component of decisionmaking in contaminated sediment management, and an important driving force is the presence of uncertainty. Uncertainties accumulate at all stages of site assessment and modeling, and are magnified during scaling of cause-and-effect relationships from laboratory to field scale, from site scale to regional scale, and during extrapolation of relationships beyond their range of input measurements or beyond the site where the relationships/models were established. Even when preventive measures are based on sound planning, sampling [37] and analytical methods [38] aimed at eliminating and minimizing some sources of error and bias, uncertainties always remain. Nevertheless, the element of uncertainty in the management of contaminated sediments is often treated inadequately [39], or not addressed at all. For example, unquantified uncertainties can force extremely conservative estimates [40], which can lead to high inefficiencies in the allocation of sparse resources for remediation. Most frequently, uncertainty is expressed in the form of confidence intervals, or by incorporation of safety factors based on best "professional judgment." But these measures and strategies incorporate assumptions about the nature (such as normal distributions) and magnitude of uncertainty, which are rarely tested and which vary along with sampling and measurement methods, models, and site variability and other site characteristics.

Several approaches are available for system modeling and decision-making under uncertainty, depending on the data, the magnitude and the acceptable level of uncertainty. Weight-of-evidence (WOE) approaches deal with large uncertainties by integrating multiple lines of evidence into a decision measure using methods ranging from best professional judgment to weighted scoring and statistical summaries/comparisons to reference situations [41]. WOE is most often applied in risk assessment, but its methods are valuable in any situation where uncertainties are large and/or multiple lines of evidence for the same decision requirement are available.

When systems are better understood and mechanistic models available, the inputs can be treated as random variables. Uncertainties of these inputs (parameters/coefficients and variables) can be expressed in the form of probability distributions (using regression, analytical error parameters, or best professional judgment in the context of Bayesian prior and posterior probabilities). These uncertainties are then propagated to the model output via mathematical analysis for simple models and via stochastic simulation using Monte Carlo analysis, Latin hypercube sampling, or bootstrap analysis [42]. The uncertainty evaluation of input parameters for the deterministic models must often rely on professional judgment, in particular, when values of parameters are scattered in the literature and were derived in different experiments (or sites), by different investigators, under different experimental (or site) conditions [40,43]. When experiments are repeated, the regression of a functional relationship will yield estimates and standard errors that are used as parameter estimators in appropriate distributions, e.g., the Gaussian distribution [44].

In the case of variables (i.e., sampled data), probability distributions can be generated using, for example, the known precision of the instrument. If the sampling is spatially distributed, local distributions at all sampled and unsampled locations can be derived using kriging approaches or stochastic simulation. Once input distributions are quantified, values for each input variable and model parameter are randomly drawn from their probability distributions using, for example, a Monte Carlo approach, preserving correlations among the inputs if applicable. The resulting combination of input values is used in the model (e.g., sediment fate and transport, contaminant flux) to generate a realization [45-47]. The process is repeated, while the nature of the sampling ensures that the realizations are equally probable, allowing a statistical summary of the model outputs. Uncertainties associated with scaling (e.g., laboratory derived contaminant degradation used in site models) or aggregation can be assessed in the context of validation, weight-of-evidence approaches [43], and by gathering additional data that represent the larger-scale patterns of variability [48-50].

\section{Spatial Patterns and Scaling}

Spatial structures may be explained in various aspects by the way data are collected and summarized. Dale et al. [51] provide an overview of most of the mathematic tools used for spatial data analysis, and quantitatively explain the differences among the approaches including the use of variograms and fractal dimensions among the 28 approaches. It was concluded that, in spite of the diversity of the backgrounds and motivation that give rise to the methods described in their paper, there are some obvious conceptual themes and mathematical similarities that tie them together. While one may not expect that any single method can reveal all the important features of any data set, it should be noticed that the results of different analyses may not be fully independent [51]. Depending on the specific questions to be answered about spatial characteristics of a given dataset, new approaches are yet to be developed. 


\subsection{Geostatistical Approaches}

The applications of geostatistical techniques to the spatial analysis of sediments are recent and few. Barabás et al. [52] modeled spatial uncertainty in dioxin contamination in three dimensions using indicator kriging in Passaic River sediments; Murray et al. [53] mapped the extent of DDE contaminated sediment thickness on the Palos Verdes shelf using sequential indicator simulation, while Fioole et al. [54] developed the SURFIS computer program, to integrate geostatistical methods in order to account for random error in the optimization of dredging of contaminated sediments with digital terrain models (DTMs). To further explore the applicability of geostatistics-based spatial analysis, it is useful to provide some background on the assumptions underpinning these techniques.

One of the central concepts of spatial analysis is the variogram. A variogram is a mathematical expression of dissimilarity (e.g., of concentrations) as a function of separation distance between any two points in space [55]. A generic variogram is shown in Fig. 4, where $h$ is the distance between any two locations, range indicates the range of interaction between location pairs, sill and nugget effect indicate the possible maximum and minimum variation, and the curve in this graph explains the relative strength of interaction in terms of the distance of the locations apart.

The variogram-based approach models an attribute $z$ at each unsampled location $\mathbf{u}$ as a random variable $Z(\mathbf{u})$ with a conditional cumulative distribution function (ccdf) $F(\mathbf{u}$; $z \mid(n))$, conditional to $n$ neighboring data $z\left(\mathbf{u}_{a}\right)$. The ccdf fully captures the uncertainty at $\mathbf{u}$ since it gives the probability that the unknown is no greater than any given threshold $z$ [55]:

$F(\mathbf{u} ; z \mid(n))=\operatorname{Prob}\{Z(\mathbf{u}) \leq z \mid(n)\}$

Parametric and non-parametric methods exist to model attribute ccdfs. Indicator kriging (IK) is a non-parametric approach, with the advantages that the shape of the ccdfs is derived using spatially varying information rather than assuming a global analytical expression (such as a parametric Gaussian model). IK is also able to integrate these with uncertainties due to analytical methods [56], as well as to incorporate additional information on correlated secondary attributes and soft information (such as soil maps, or qualitative field observations) into the modeling procedure. Least squares interpolation algorithms such as kriging tend to smooth out local details of the spatial variation of the attribute with small values typically overestimated and large values un-

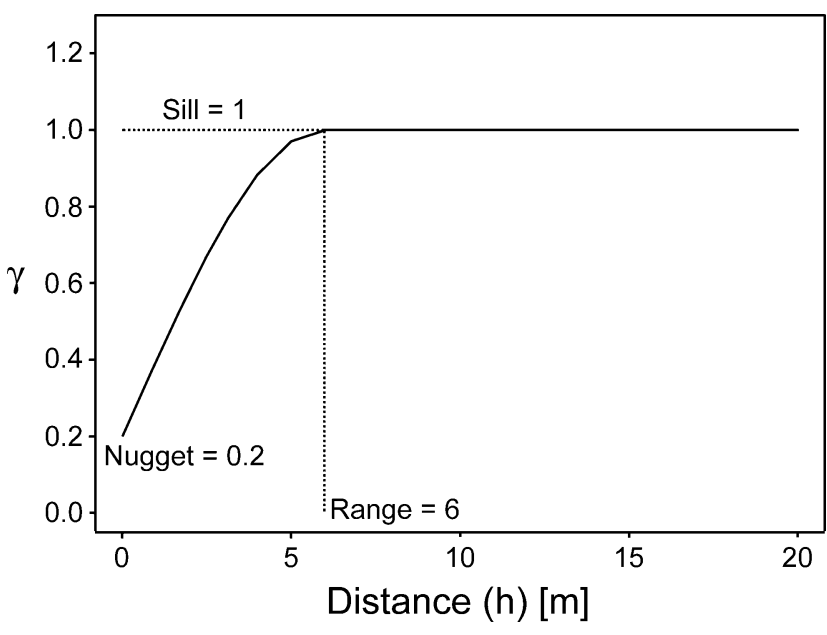

Figure 4. Variogram.

derestimated. To avoid these errors, stochastic simulation is increasingly preferred to kriging for environmental assessment applications such as delineation of contaminated areas [55,57-59], or the modeling of groundwater flow in heterogeneous aquifers [57,60-64]. The set of alternative realizations generated provides a quantitative measure of spatial uncertainty. Features that appear consistently on most of the simulated maps are deemed certain, as expressed by a corresponding local ccdf summarizing the probability distribution of the attribute at each simulated grid point. The uncertainty can then be summarized into probability maps, risk maps, or maps of false positives and false negatives [65]. Such results can aid in a more scientifically grounded assessment of safety factors and a more realistic and comprehensive formulation of confidence intervals. These maps are also well suited to the communication of uncertainties to non-scientific communities. An example is illustrated in Fig. 5 for a dioxin dataset, where geostatistics was used to generate a probability map, which

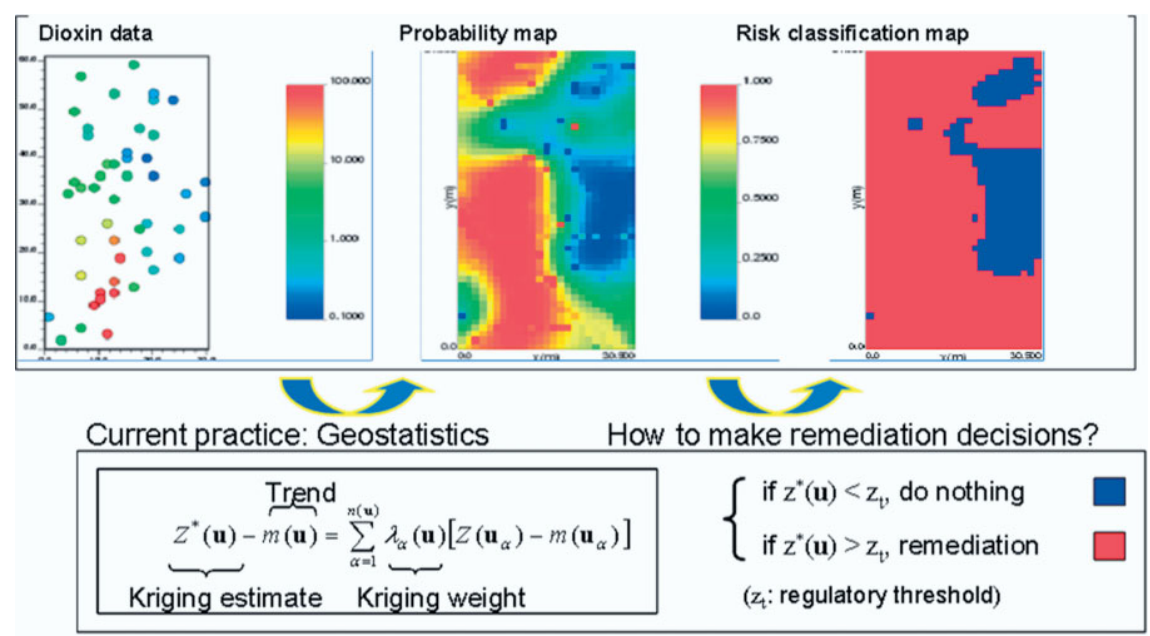

Figure 5. Site characterization and risk classification for remedial decision-making (adapted from Saito and Goovaerts, 2003 [66]) 
can be translated into a risk classification map for remedial decision-making when certain threshold values are considered in the final analysis. Approaches such as these are gaining momentum in the regulatory community in an effort to optimize remedial costs and benefits.

\subsection{Multi-Scale Modeling (M-Scale Model)}

Whereas geostatistical methods mostly implicitly incorporate the scale in the interpolation of known values, by evaluating the point-to-point distances in the overall smoothing of unknown values, multi-scale modeling explicitly integrate measurements made at various scales. The "smoothing effect" of geostatistic models comes from the assumption that either a fixed unknown value or a smooth function of trend values applies within the search neighborhood of estimation. A recently developed model, which will be expanded upon here, is M-Scale [67-69]. The statistical premise of the M-Scale model is that the variation of values at different spatial scales is heuristically related. In other words, if samples are collected at the "point scale" (e.g., single cores selected from large sites), the variation of parameters collected within the core are propagated to higher scales by taking into account the correlations of the local averages between scales. These correlations are informed by the variation of local averages at each scale. Taken together, the contributions of variation at each scale are weighted and aggregated into a best linear unbiased estimator, as shown in Fig. 6.

The model not only serves as a tool to evaluate parameter relationships over different scales by their covariances and data uncertainty, but also makes further use of these covariances and data uncertainty as the basis for a precision-optimized estimator. Information from each scale is weighted by the projected similarity to the scales of interest, with adjustments incorporating the different precision they provide.

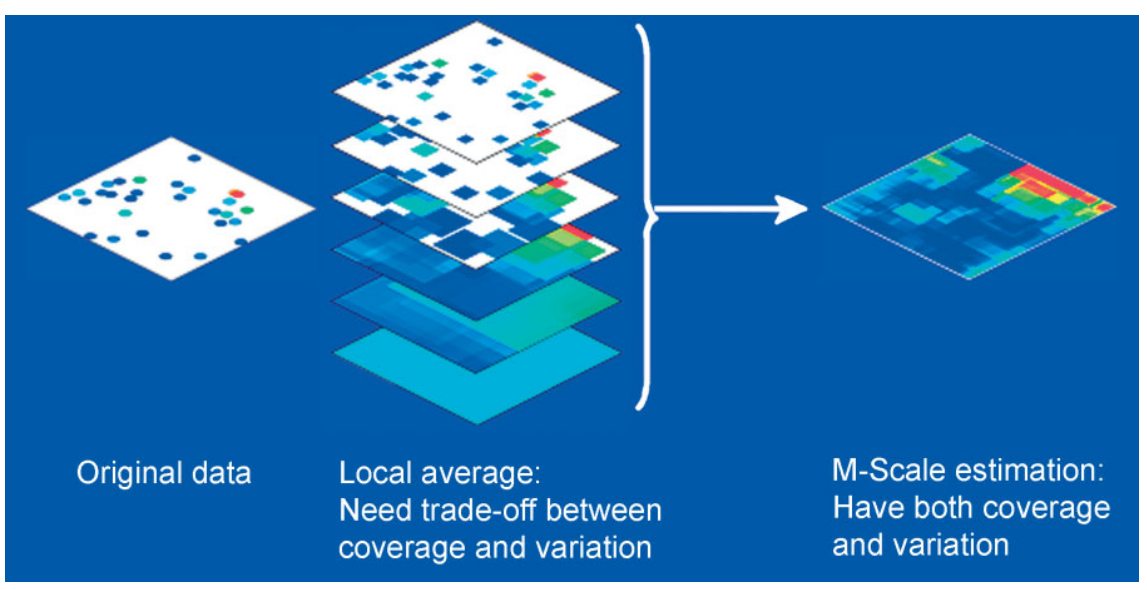

Figure 6. Schematic components of the M-Scale model: Calculate local averages at different scales, determine covariance between scales, and use covariance between scales at sampled locations to estimate variation at each scale.
Unlike conventional geostatistical tools, which are based on point-to-point spatial structures, the multi-scale model introduces a new framework for spatial analysis in which regional values at different scales are anchored by the correlations of each other [67].

The estimation mechanism is conceptualized in Fig. 6, except that the kriging estimate is now for the local average of a target scale of interest, the trend on both sides of the equations are the local average calculated from the smallest scale that contains data, and the true data includes every local averages calculated from all different scales. Consequently, the search neighborhood will be the largest scale of estimation, while the trend will depend on the available size of scale rather than a pre-defined smooth function over the search neighborhood.

\section{Spatial Pattern of Measurements for Microbial Abundance and Activity}

Scientists conceive microbial abundance and activities using different metrics and endpoints. How the abundance and activities should be sampled and measured, consequently, varies widely dependent on the different objectives for subsequent research or for decision-making purposes. Moreover, microbial endpoints are rarely extrapolated in space and across scales. Sampling strategies, among all the factors that could alter the explanation of spatial patterns, aim to capture the possible minimum and maximum distance of interaction between locations that the scientists could conclude as the range of spatial structures. Nunan et al. [70], for example, collected 49 random samples within a topsoil volume of a $300 \mathrm{~cm}$ by $300 \mathrm{~cm}$ cross-section area with a depth of $30 \mathrm{~cm}$. The bacterial abundance was measured by slicing the soil sample and processing the cross-sections using automatic image tools that allowed for differentiation of images within a spatial support of $282 \mu \mathrm{m}^{2}$. It was concluded, based on these results, that a spatial structure of $100 \mu \mathrm{m}$ to $50 \mathrm{~cm}$ adequately captures the microbial abundance distribution in this system [70].

In some research, sampling is conducted to observe a larger interaction range. Gaston et al. [71] used four randomly selected samples along the sides of a $2 \mathrm{~m}$ by $2 \mathrm{~m}$ square area at grid nodes 60 by 60 meter square grids. The local variation within the $2 \mathrm{~m}$ by $2 \mathrm{~m}$ square area can thus be detected, and the interaction range of larger than 60 meter would also be evaluated. This study indicates an interaction range varying from no interaction at all, to all distances in the research area for attributes including 
fluorescein diacetate activity, $\mathrm{pH}$, organic carbon, and soil composition (clay, sand). Another meter-scale sampling scheme was reported by Writh [72] who measured soil microbial biomass using a physiological, substrate-induced respiration method. The sampling approach in this study involves a local lag distance of $2 \mathrm{~m}$, medium lag distance of $1.7 \mathrm{~km}$ and demonstrated a spatial structure within the range of $75 \mathrm{~m}$.

Beliaeff and Cochard [73] presented a sampling scheme for an even coarser spatial resolution. Fecal coliforms were measured in shellfish at a spatial distance of about 250 meters apart at any convenient location in the study site of $6.5 \mathrm{~km}$ by $1.5 \mathrm{~km}$. An interaction range of 920 meters up to all distances is reported, varying from season to season. Robertson et al. [74] measured the impact of chloroform fumigation on the soil microbial biomass, using the serial dilution method (most probable number, MPN) to evaluate the microbial population counts. The biogeochemistry attributes measured in their paper also included gravel content, bulk density, sand content, silt content, clay content, gravimetric moisture, different nitrogen content and organic phosphate. The sampling scheme involved 796 random samples within the study area of 48 ha. No variation of population size was found over the site while for microbial biomass, some spatial structure does exist within a distance of around $30 \mathrm{~m} \mathrm{[74].}$

Oline and Grant [75] used a nested sampling scheme in order to attain a multi-scale variation for their biogeochemical attributes. Water content, $\mathrm{pH}$, organic matter and soil microbial biomass were measured in different scales ranging from $1 \mathrm{~cm}$ to $1 \mathrm{~km}$ by randomly selecting a subdivision from a larger scale area, and divided into 10 subdivisions for further selection. A varying interaction range was reported from as small as $10 \mathrm{~m}$ to as large as $1 \mathrm{~km}$ [75].

No general rules for the range of interaction among attribute values are applicable so far in ecological studies; neither is there for the overall variation over the mapped extent. An exploratory data analysis is thus required before further analysis and decision can be made based on screening-level sampling strategies, in order to avoid any unnecessary sampling over the site of interest. Hydrogeology and biogeochemistry are likely factors that affect the spatial pattern of microbial attributes as transfer functions that propagate the uncertainties associated with point measurements. The examples shown below show the results of two different datasets using both a geostatistical technique (ordinary kriging) and the M-Scale model.

\subsection{Microbial Dechlorination Fingerprints in Passaic River Sediments (NJ)}

The Passaic River has been contaminated with dioxins from a wide range of point and diffuse sources of industrial and urban (combined sewage overflows) origin. As dioxins are present in the form of multiple compounds and distributions of the individual compounds [76], chemometric data analysis can be applied to unmix patterns into contributing sources. Using polytopic vector analysis (PVA), a stable probabilistic dechlorination fingerprint was isolated that explained up to $7 \%$ of the patterns variance across 396 sediment data collected in xyz direction [77]. The weighted contribution of the (microbial) natural attenuation pattern is shown in Fig. 7 on a linearized plot of the Passaic River.

A comparison of Ordinary Kriging (OK) estimate (left) with M-Scale estimation (right) for a selected cross-section of the river (see Fig. 8) indicates that M-Scale appears to preserve local features in the spatial distribution of the dechlorination fingerprint, and that $\mathrm{OK}$ smooths out the concentration distributions.

To evaluate the predictive capability of both models, each of the 396 values was removed and re-estimated using both models. The resulting plot of actual vs. estimated values is shown on a Q-Q plot (see Fig. 9) representing graphically how well the model estimates predict the actual values (deviation from the $45^{\circ}$ line). These results further confirm that the M-Scale estimation generally reflects the data across the entire magnitude range, while Ordinary Kriging tends to underestimate higher values and overestimate lower values. We propose here to use a reproduction coefficient as an in-

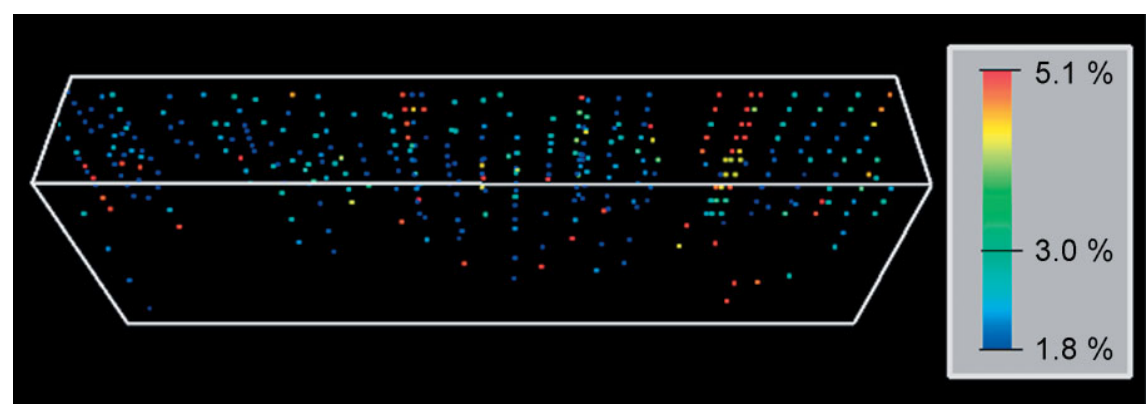

Figure 7. Spatial distribution of dechlorination fingerprints (color-scale indicates percent contribution of the fingerprint endmember to the overall sample variance) (according to Adriaens and Li, 2005 [67]).

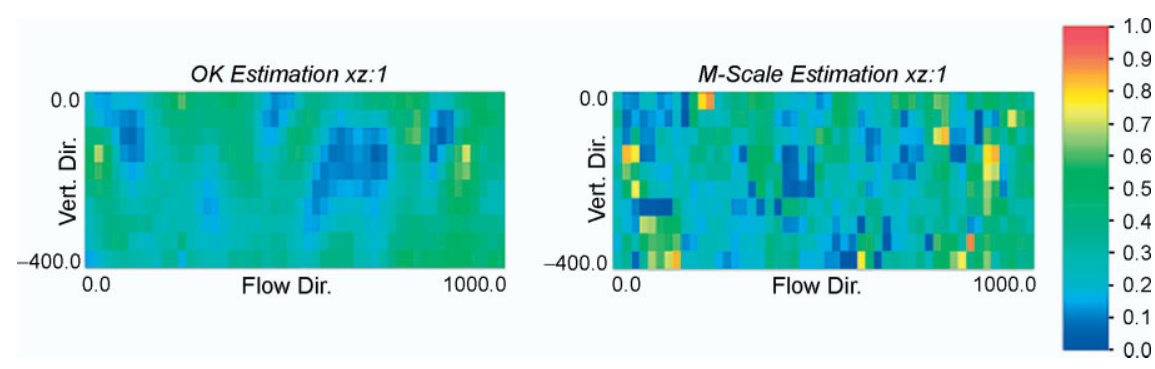

Figure 8. Estimation maps by Ordinary Kriging (OK) and M-Scale Models. 


\section{OK Cross-Validation}

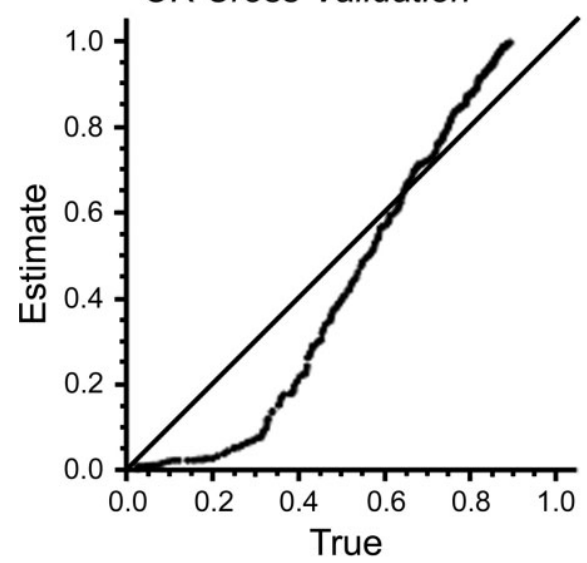

M-Scale Cross-Validation

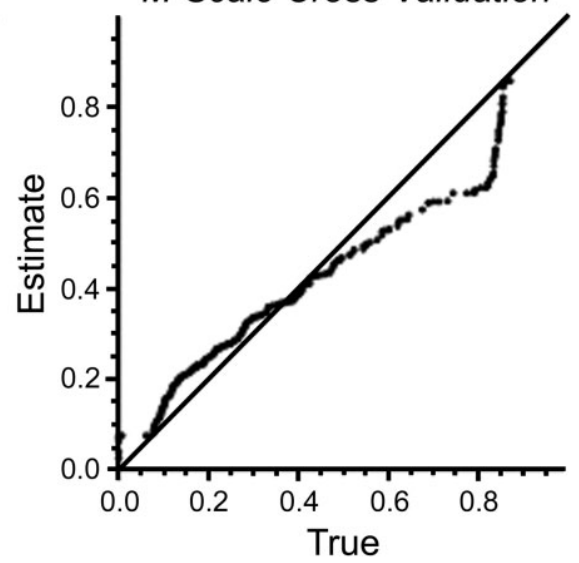

The Anacostia River microbial data represent a spatially sparse dataset of values ranging over two orders of magnitude for microbial abundance $\left(10^{5}-10^{7}\right)$ and for microbial activity ( $\%$ of total $0.7-65 \%$ ). Using a similar approach as demonstrated for the Passaic River samples, the results for microbial abundance are presented in Fig. 11.

The outcome shows similar observations as with the much larger dioxin dataset. M-Scale preserves local features in the data, and flows the trendline for cross-validated samples with greater fidelity than $\mathrm{OK}$. It is not clear what the deviations from the

Figure 9. Q-Q plots from Ordinary Kriging (OK) and M-Scale Models

dex of the similarity between estimate and true values on the basis of their correlation coefficient respective to the true value:

$\mathrm{r}^{\prime}=\frac{\sum_{\mathrm{i}=1}^{\mathrm{n}}\left(\hat{\mathrm{z}}_{\mathrm{i}}-\overline{\mathrm{z}}\right)\left(\mathrm{z}_{\mathrm{i}}-\overline{\mathrm{z}}\right)}{\sum_{\mathrm{i}=1}^{\mathrm{n}}\left(\mathrm{z}_{\mathrm{i}}-\overline{\mathrm{z}}\right)^{2}}$

where $z_{i}$ is the true value, $\hat{z}_{i}$ is the re-estimated $z_{i}$, and $n$ is the total number of pairs of estimate and true values. The reproduction coefficient becomes unity when the paired values are exactly the same or when all the differences average out. The results for $\mathrm{OK}$ and $\mathrm{M}$-Scale model are 0.382 and 0.414 , respectively, showing the advantage of using of M-Scale model on the overall similarity between estimation pairs of all locations.

An alternative validation approach is the use of bootstrapping methodology, which is based on random sub-sampling of the dataset, followed by re-estimation of the entire dataset removed. In this particular case, 20 datasets each containing 100 datapoints were removed and re-estimated using both methods. Substantially more data scatter is observed, but the prediction (mean \pm 1 s.d.) still captures the $45^{\circ}$ line in the case of M-Scale.

\subsection{Microbial Abundance and Activity Data in the Anacostia River (Washington, DC)}

The Anacostia River is contaminated with heavy metals, polycyclic aromatic hydrocarbons and polychlorinated biphenyls. In situ capping strategies are explored to reduce risk from contaminants to the ecosystem. Aside from conventional sand caps, reactive caps including Aquablok ${ }^{\circledR}$ (expanding clay coated granular material) and coke-embedded geotextiles (to increase contaminant sorption) have been implemented (Fig. 10 shows uncapped, sand and Aquablok ${ }^{\circledR}$ caps; covering approximately $1,012 \mathrm{~m}^{2}$ each). Co-located samples were collected based on sediment cores, and were analyzed for microbial abundance (using PicoGreen DNA stain) and metabolic competence (using CTC, 5-cyano-2,3ditolyl tetrazolium chloride). trend line can be ascribed to at this time, except for that a similar number of scales and weighting of the scales was used as for the much larger dioxin dataset. We are currently exploring an optimization approach for these two variables. The dataset for microbial activity (see Fig. 12) shows that despite the fact that M-Scale preserves local variation, the cross-validation of the data does not improve over that for OK.

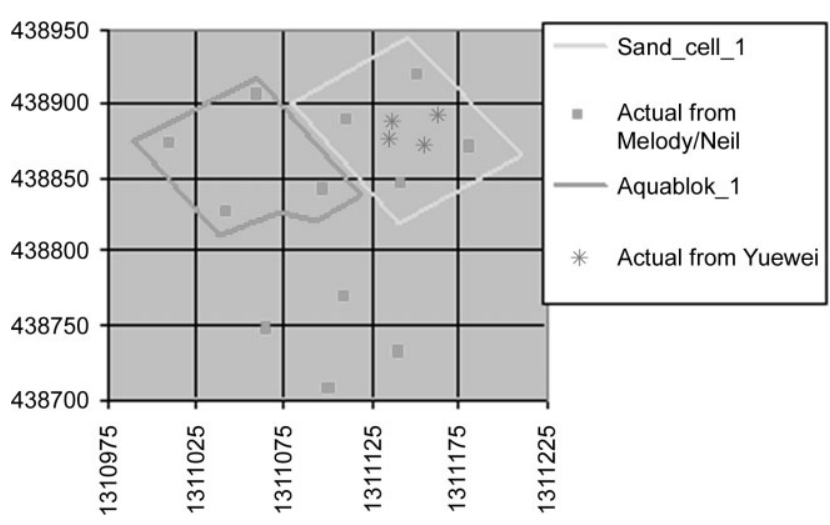

Figure 10. Co-located sediment cores from the Anacostia River capping demonstration site.

\section{Conclusions}

The scaling of microbial processes and applications continues to be challenging, both from the perspective of developing appropriate sampling designs for site characterization, and for the appropriate scale of remedial designs. The latter is of particular importance when in situ remediation strategies, such as bioremediation, are envisioned, as these processes attempt to capitalize on the confluence of in situ destructive processes and engineered intervention. Based on the information presented earlier, multi-scale data integration using geostatistical models may afford an opportunity to align information for probabilistic optimization of technology siting.

The example (see Fig. 13) integrates information of extracted reactive patterns from contaminant concentrations 

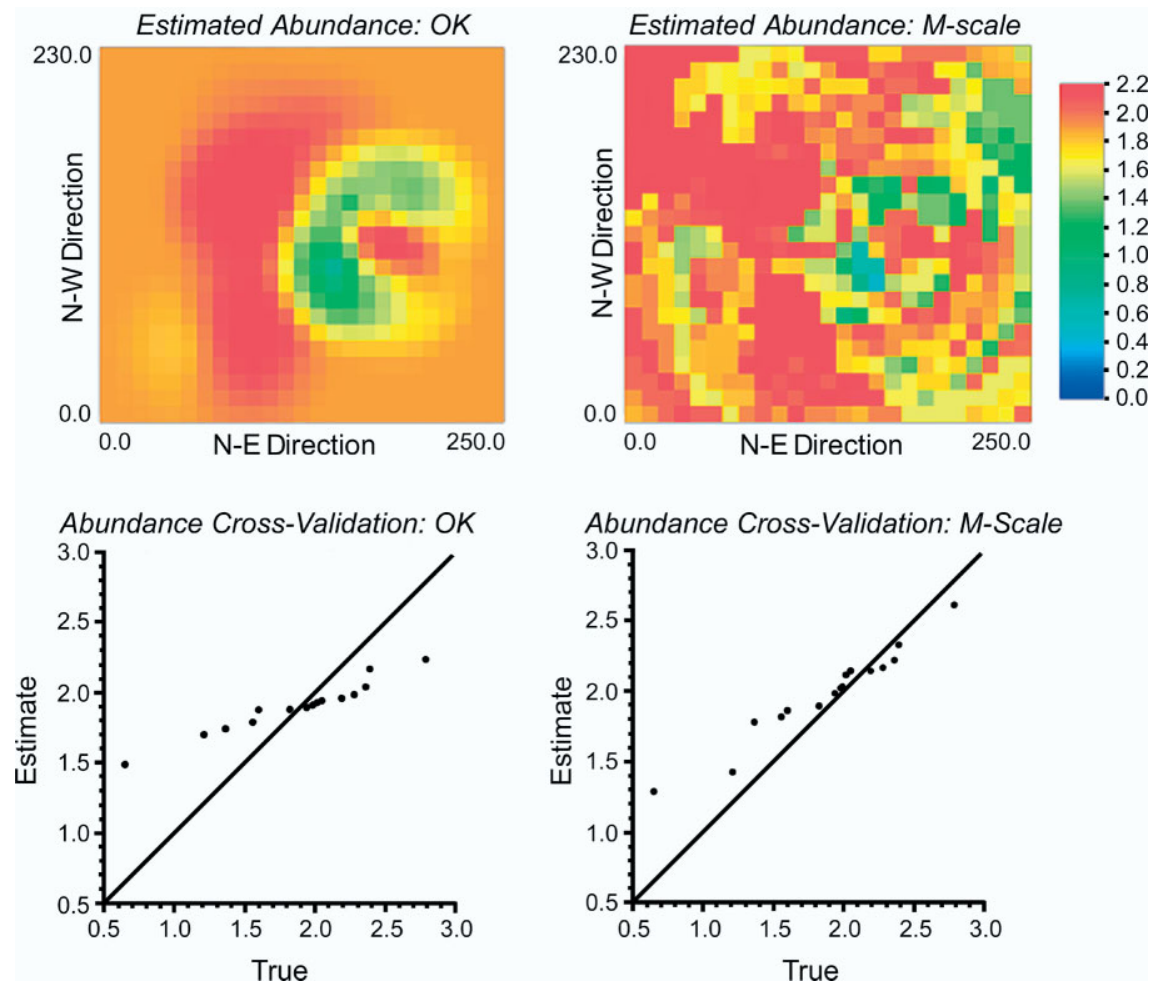

Figure 11. Multi-scale estimation (right) and spatial interpolation (left) of microbial abundance.
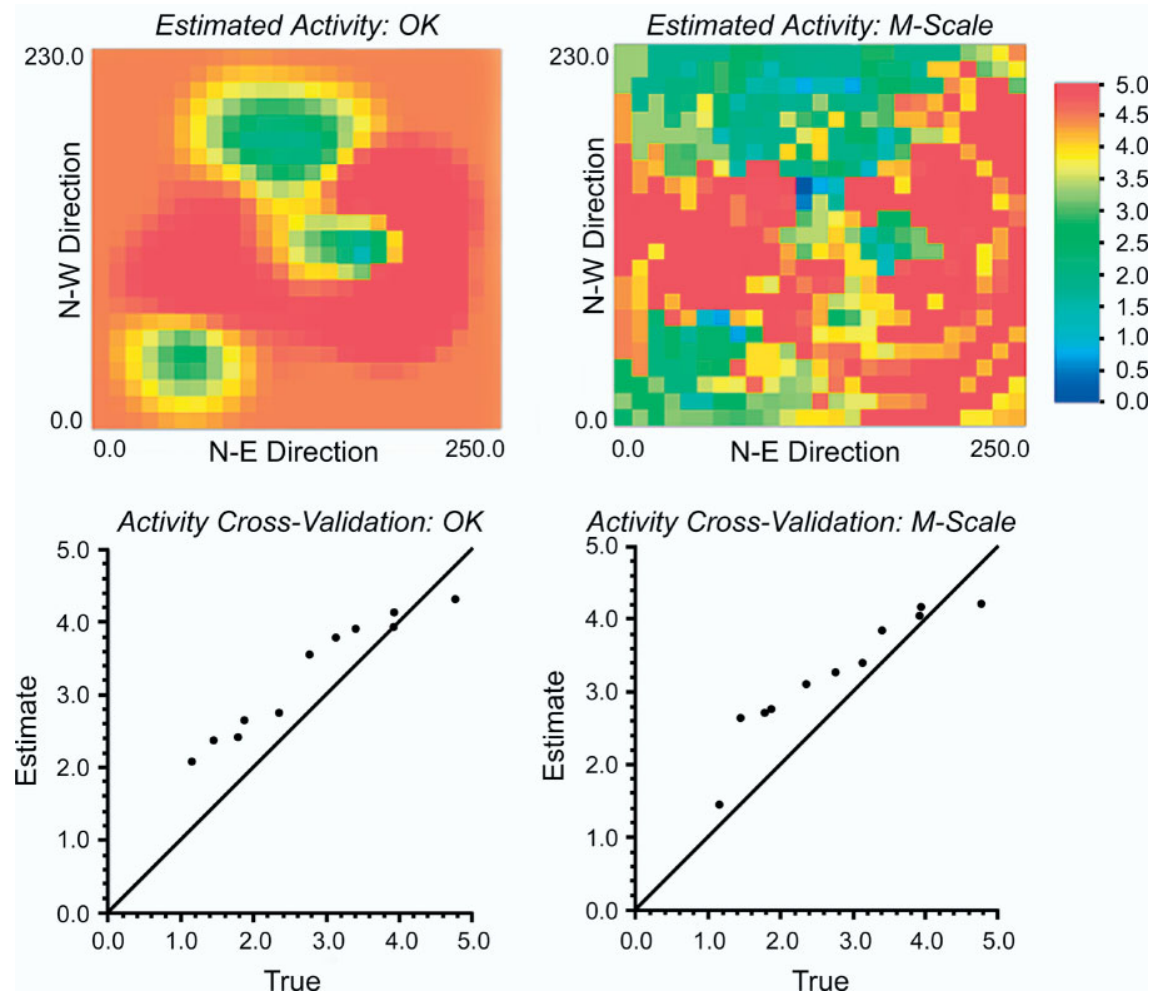

Figure 12. Multi-scale estimation (right) and spatial interpolation (left) of microbial activity data. 


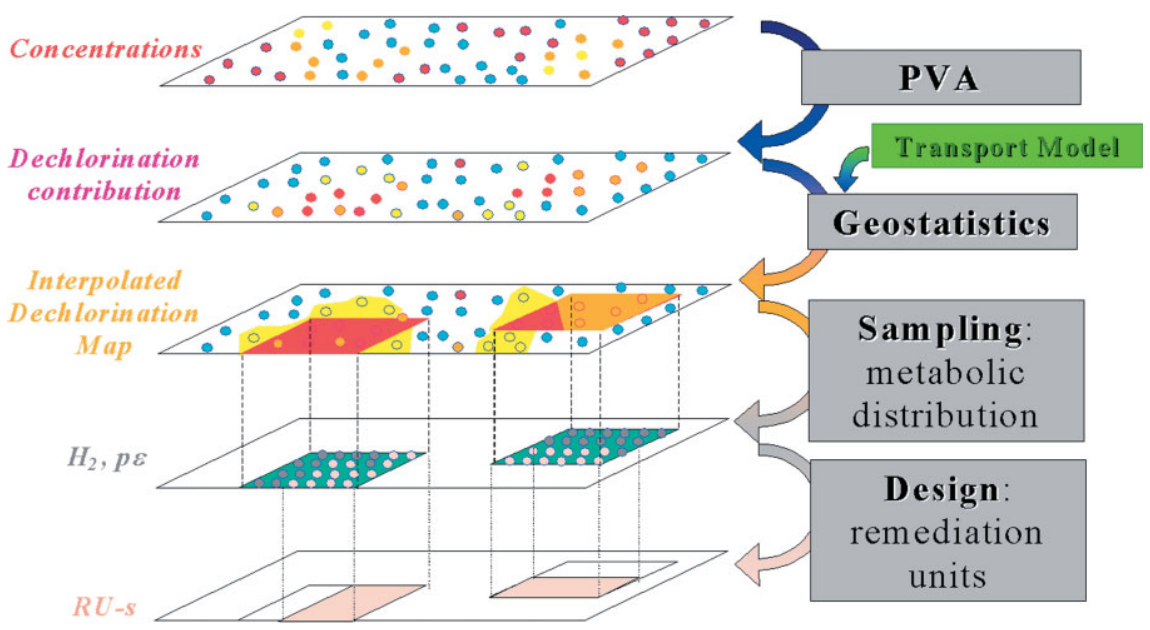

Figure 13. Probabilistic optimization of remedial unit siting (according to Barabas, 2003 [77]).
[11] L.N. Reddi, R.S. Govindaraju, Particle mobilization in sand-clay mixtures and facilitation of contaminant removal, in Geotechnical Special Publication, ASCE, New York, USA 1995, 1222-1236.

[12] S.E. Apitz, D. B. Chadwick, V. J. Kirtay, Pathway ranking for in place sediment management (PRISM): Site 1 Demonstration, SERDP Review Meeting, Washington, DC, USA, December 3-5, 2002.

[13] N. J. Fendinger, D. D. Adams, D. E. Glotfelty, The role of gas ebullition in the transport of organic contaminants from sediments, Sci. Total Environ. 1992, 112, 189-201.

[14] P. Adriaens, A. L. Barkovskii, I.D. Albrecht, Fate of chlorinated aromatic compounds in soils and sediments, in Bioremediation of Contaminated Soils (Ed: D.C. Adriano, J.-M. Bollag, W. T. Frankenberger, R. Sims), American Society of Agronomy Monograph, Soil Science Society of America Press, Madison, WI, USA 1999, 175-212.

which are mapped out using geostatistical (or multi-scale) models. When this information is overlain with microbial attribute (abundance, activity) maps, probabilistic remedial units (RUs) can be determined that capture target information for successful candidates for the implementation or interpretation of bioremediation applications.

\section{Acknowledgements}

The authors acknowledge support from the DOD/DOE/ EPA Strategic Environmental Research and Development Program (SERDP) through a grant awarded to P.A.

Received: January 20, 2006 [ELS 127] Received in revised form: March 10, 2006 Accepted: March 23, 2006

\section{References}

[1] Contaminated Sediments in Ports and Waterways: Cleanup Strategies and Technologies (Ed: National Research Council, NRC), National Academy Press, Washington DC, USA 1997.

[2] T. C. Winter, Subaqueous capping and natural recovery: Understanding the hydrogeologic setting at contaminated sites, in DOER Technical Notes Collection (TN DOER-C26), U.S. Army Engineer Research and Development Center, Vicksburg, (MS) USA 2002. http://www.wes.army.mil/el/dots/doer

[3] T.E. Myers, R. P. Gambrell, M. E. Tittlebaum, Design of an improved column leaching apparatus for sediments and dredged material, Miscellaneous Paper D-91-3 (Ed: U.S. Army Corps of Engineers Waterways Experiment Station), Vicksburg (MS), USA 1991.

[4] S. E. Apitz,. J. W. Davis, K. Finkelstein, D. L. Hohreiter, R. Hoke, R. H Jensen, et al., Critical issues for contaminated sediment management, in MESO-02-TM-01, 2002. http://meso.spawar.navy.mil/docs/MESO-02TM-01.pdf

[5] A. Kandiah, Fundamental aspects of surface erosion of cohesive sediments, PhD Thesis, University of California, Davis, USA 1974.

[6] Y. L. Lau, Influence of antecedent conditions of critical shear stress of bed sediments, Water Res. 2000, 34 (2), 663-667.

[7] R. B. Krone, Effects of bed structure on erosion of cohesive sediments, J. Hydraulic Eng. 1999, 125 (12), 1297-1301.

[8] K. E. Dennett, T.W. Sturm, A. Amirtharajah, T. Mahmood, Flume studies on the erosion of cohesive sediments, Proc. of the 1st International Conf. on Water Resources, San Antonio, TX, USA 1995, 199-203.

[9] R. C. Gularte, W. E. Kelly, V. A Naeeri, Erosion of cohesive sediment as a rate process, Ocean Eng. 1995, 7 (4), 539-551.

[10] T.M. Parchure, A. J. Mehta, Erosion of soft cohesive sediment deposits, J. Hydraulic Eng. 1985, 111 (10), 1308-1326.
[15] P. Adriaens, C. Gruden, M. L. McCormick, Biogeochemistry of halogenated hydrocarbons, in Treatise of Geochemistry, Vol. 9: Environmental Geochemistry (Ed: B.S. Sherwood-Lollar), Elsevier, Amsterdam, The Netherlands 2003, 511-541.

[16] M. R. Palermo, T. A. Thompson, F. Swed, White Paper No. 6B: In-situ capping as a remedy component for the lower fox river, Response to a Document by the Johnson Compan, Ecosystem-based Rehabilitation Plan, in An Integrated Plan for Habitat Enhancement and Expedited Exposure Reduction in the Lower Fox River and Green Bay, December 2002.

[17] D. G. Capone, R. P. Kiene, Comparison of microbial dynamics in marine and freshwater sediments: Contrasts in anaerobic carbon catabolism, Limnol. Oceanogr. 1988, 33, 725-749.

[18] B. Ollivier, P. Caumette, J.-L. Garcia, R. A. Mah, Anaerobic bacteria from hypersaline environments, Microbiol. Rev. 1994, 58, 27-38.

[19] P. Bonin, E. R. Ranaivoson, N. Raymond, A. Chalamet, J. C. Bertrand, Evidence for denitrification in marine sediment highly contaminated by petroleum products, Mar. Pollut. Bull. 1994, 28, 89-95.

[20] B. L. Nowicki, The effect of temperature, oxygen, salinity, and nutrient enrichment on estuarine denitrification rates measured with a modified nitrogen gas flux technique, Est. Coast Shelf Sci. 1994, 38, 137-156.

[21] D. R. Lovley, Dissimilatory Fe(III) and Mn(IV) reduction, Microbiol. Rev. 1991, 55, 259-87.

[22] E. M. Murphy, J. A. Schramke, Estimation of microbial respiration rates in groundwater by geochemical modeling constrained with stable isotopes, Geochim. Cosmochim. Acta 1998, 62 (21-22), 3395-3406.

[23] B. Gevao, J. Hamilton-Taylor, C. Murdoch, K. C. Jones, M. Kelly, B. J. Tabner, Depositional time trends and remobilization of PCBs in lake sediments, Environ. Sci. Technol. 1997, 31, 3274-3280.

[24] R. Lohmann, E. Nelson, S. J. Eisenreich, K. C. Jones, Evidence for dynamic air-water exchange of PCDD/Fs: A study in the Raritan Bay/ Hudson River Estuary, Environ. Sci. Technol. 2000, 34, 3086-3093.

[25] Q.S. Fu, A.L. Barkovskii, P. Adriaens, Dioxin cycling in aquatic sediments: The Passaic River estuary, Chemosphere 2001, 43 (4-7), 643-648.

[26] G. E. Claypool, K. A. Kvenvolden, Methane and other hydrocarbon gases in marine sediments, Ann. Rev. Earth Planet. Sci. 1983, 11, 299-327.

[27] T. C. E. van Weering, G. T. Klaver, R. A. Prins, Gas in marine sediments: An introduction, Marine Geol. 1997, 137, 1-3.

[28] P. Casper, S. C. Maberly, G. H. Hall, B. J. Finlay, Fluxes of methane and carbon dioxide from a small productive lake to the atmosphere, Biogeochem. 2000, 49, 1-19.

[29] G. D. Ginsburg, V. A. Soloviev, Methane migration within the submarine gas-hydrate stability zone under deep-water conditions, Marine Geol. 1997, 137, 49-57.

[30] B. Elberling, Gas phase diffusion coefficient in cemented porous media, J. Hydrol. 1996, 178, 93-108.

[31] F. Rothfuss, R. Conrad, Effect of gas bubbles on the diffusive flux of methane in anoxic paddy soil, Limnol. Ocean. 1998, 43, 1511-1518.

[32] G. C. Bugna, J. P. Chanton, J. E. Cable, W. C. Burnett, P. H. Cable, The importance of groundwater discharge to the methane budgets of nearshore and continental shelf waters of the northeastern Gulf of Mexico, Geochim. Cosmochim. Acta 1996, 60, 4735-4746. 
[33] Y. Matsumoto, Y. Ishii, K. Shimura, Gas generation in canals of Tokyo port, in Proceedings on the 12th U.S./Japan Experts Meeting on the Management of Bottom Sediments Containing Toxic Substances, November 11-14, 1986, Yokohama, Japan (Ed: T. R. Patin), United States Army Corps of Engineers, Water Resources Support Center, USA 1992.

[34] Handbook of Hydrology (Ed: D. R. Maidment), McGraw-Hill, Inc. New York, USA 1992.

[35] P. Goovaerts, Geostatistics for Natural Resources Evaluation, Oxford University Press, New York, USA 1997.

[36] F. Poschet, A. H. Geeraerda, N. Scheerlinck, B. M. Nicolaï, J. F. van Impe, Monte Carlo analysis as a tool to incorporate variation on experimental data in predictive microbiology, Food Microbiol. 2003, 20, 285-295.

[37] G. E. Batley, G. A. Burton, P. M. Chapman, V. E. Forbes, Uncertainties in sediment quality weight-of-evidence (WOE) assessments, Human Ecol. Risk Assess. 2002, 8, 1517-1547.

[38] Guidance for Data Quality Assessment: Practical Methods for Data Analysis (QA/G-9 QA00 Update), (Ed: United States Environmental Protection Agency, US EPA), EPA 600/R-96/084, U.S. Government Printing Office, Washington D.C., USA 2000.

[39] G. W. Suter, Statistics and risk assessment, Proc. of the Lukacs Symposium on Frontiers of Environmental and Ecological Statistics for the 21st Century: Synergistic Challenges, Opportunities and Directions for Statistics, Ecology, Environment, and Society Department of Mathematics and Statistics, Bowling Green State University, Bowling Green, $\mathrm{OH}$, USA, April 23-25, 1999. http://www-math.bgsu.edu/symposium/abstract/node4.html

[40] I. Linkov, D. Burmistrov, J. Cura, T. S. Bridges, Risk-based management of contaminated sediments: Consideration of spatial and temporal patterns in exposure modeling, Environ. Sci. Technol. 2002, 36, 238-246.

[41] P. M. Chapman, B. G. McDonald, G. S. Lawrence, Weight-of-evidence issues and frameworks for sediment quality (and other) assessments, Human Ecol. Risk Assess. 2002, 8, 1489-1515.

[42] B. Efron, Estimating the error rate of a prediction rule: Improvement on cross-validation, J. Amer. Stat. Assoc. 1983, 78 (382), 316-331.

[43] L. J. Steinberg, K. H. Reckhow, R. L. Wolpert, Characterization of parameters in mechanistic models: A case study of a PCB fate and transport model, Ecol. Modeling 1997, 97, 35-46.

[44] P. Goovaerts, J. Semrau, S. Lontoh, Monte Carlo analysis of uncertainty attached to microbial pollutant degradation rates, Environ. Sci. Technol. 2001, 35, 3924-3930.

[45] C. E. Papadopoulos, H. Yeung, Uncertainty estimation and Monte Carlo simulation method, Flow Measurem. Instrument. 2001, 12, 291-298.

[46] J. U. Clarke, V. A. McFarland, Uncertainty analysis for an equilibrium partitioning-based estimator of polynuclear aromatic hydrocarbon bioaccumulation potential in sediments, Environ. Toxicol. Chem. 2000, $19,360-367$.

[47] R. E. Rossi, P. W. Borth, J. J. Tollefson, Stochastic simulation for characterizing ecological spatial patterns and appraising risk, Ecol. Applications 1993, 3, 719-735.

[48] R. J. Luxmoore, A. W. King, , M. L. Tharp, Approaches to scaling up physiologically based soil plant-models in space and time, Tree Physiol. 1991, 9, 281-292.

[49] N. Barabas, P. Goovaerts, P. Adriaens, Modified polytopic vector analysis to identify and quantify dioxin dechlorination signatures in sediments: 1. Theory, Environ. Sci. Technol. 2004, 38, 1813-1820.

[50] N. Barabas, P. Goovaerts, P. Adriaens, Modified polytopic vector analysis to identify and quantify dioxin dechlorination signatures in sediments: 2. Application to the Passaic River superfund site, Environ. Sci. Technol. 2004, 38, 1821-1827.

[51] M. R. T. Dale, P. Dixon, M.-J. Fortin, P. Legendre, D. E. Myers, M. S. Rosenberg, Conceptual and mathematical relationships among methods for spatial analysis, Ecography 2002, 25, 558-577.

[52] N. Barabás, P. Goovaerts, P. Adriaens, Geostatistical assessment and validation of uncertainty for three-dimensional dioxin data from sediments in an estuarine river, Environ. Sci. Technol. 2001, 35, 3294-3301.

[53] C. J. Murray, H. J. Lee, M. A. Hampton, Geostatistical mapping of effluent-affected sediment distribution on the Palos Verdes Shelf, Continental Shelf Res. 2002, 22, 881-897.

[54] A. Fioole, E. J. Houwing, L. M. van der Heijdt, SURFIS: A tool for designing and optimizing dredging schemes, Water Sci. Technol. 1998, 37, 103-107.

[55] P. Goovaerts, Kriging vs. stochastic simulation for risk analysis in soil contamination, in GeoENV I-Geostatistics for Environmental Applications (Ed: A. Soares, J. Gómez-Hernández, R. Froidevaux), Kluwer Academic Publishers, Dordrecht, The Netherlands 1997, 247-258.

[56] H. Saito, P. Goovaerts, Accounting for measurement error in uncertainty modeling and decision making using indicator kriging and $p$-field simulation: Application to a dioxin contaminated site, Envirometrics 2002, 13, 555-567.

[57] A. J. Desbarats, Modeling spatial variability using geostatistical simulation, in Geostatistics for Environmental and Geotechnical Applications (Ed: S. Rouhani, R. M. Srivatsava, A. J. Desbarats, M. V. Cromer, A. I. Johnson), American Society for Testing and Materials STP 1283, Philadelphia, USA 1996, 32-48.

[58] P. C. Kyriakidis, Selecting panels for remediation in contaminated soils via stochastic imaging, in Geostatistics Wollongong '96, Vol. 2 (Ed: E. Y. Baafi, N. A. Schofield), Kluwer Academic Publishers, Dordrecht, The Netherlands 1997, 973-983.

[59] S. J. Naber, B. E. Buxton, M. J. Bertoni, T. D. Scheibe, J. Warren, U.S EPA Computer system for simulating site characterization activities at superfund cleanup sites, in Geostatistics Wollongong'96 (Ed: E. Y. Baafi, N. A. Schofield), Vol.2, Kluwer Academic Publishers, Dordrecht, The Netherlands 1997, 1066-1074.

[60] G. Dagan, Stochastic modeling of groundwater flow by unconditional and conditional probabilities: 1 . Conditional simulation and the direct problem, Water Res. Research 1982, 18, 813-833.

[61] A.J. Desbarats, R.M. Srivastava, Geostatistical characterization of groundwater-flow parameters in a simulated aquifer, Water Res. Research 1991, 27, 687-698.

[62] P. K. Kitanidis, Introduction to Geostatistics: Applications in Hydrogeology, Cambridge University Press, New York, USA 1997.

[63] D. R. Morgan, J. W. Eheartand, A. J. Valocchi, Aquifer remediation design under uncertainty using a new chance constrained programming technique, Water Res. Research 1993, 29, 551-561.

[64] D. C. McKinney, M. D. Lin, Pump and treat ground-water remediation system optimization, J. Water Res. Planning Managem. 1996, 122 $128-136$.

[65] P. Goovaerts, Geostatistics in soil science: State-of-the-art and perspectives, Geoderma 1999, 89, 1-45.

[66] H. Saito, P. Goovaerts, Selective remediation of contaminated sites using a two-level multiphase strategy and geostatistics, Environ. Sci. Technol. 2003, 37, 1912-1918.

[67] P. Adriaens, M. Y. Li, Scaling contaminant distributions and contaminant processes, in Proc. of the NATO Conf. on Sediment Processes and Remediation, Bratislava, Slovakia, May 2005.

[68] P. Adriaens, M. Y. Li, M-Scale model for multi-scale estimation of dioxin data: Organohalogen compounds, in Proc. of the 25th International Symp. on Halogenated Environmental Compounds and POPs, Toronto (Ontario), Canada 2005.

[69] P. Adriaens, M. Y. Li, Scaling and uncertainty of in situ biotransformation of chlorinated dioxins in sediments of US rivers and lakes, in Proc of the International Summer School on Biomonitoring, Bioavailability and Microbial Transformation of Pollutants in Sediments and Approaches to Stimulate their Biodegradation, Italian InterUniversity Consortium "Chemistry for the Environment" INCA, 2005.

[70] N. Nunan, K. Wu, I. M. Young, J. W. Crawford, K. Ritz, In situ spatial patterns of soil bacterial populations mapped at multiple scales in an arable soil, Microb. Ecol. 2002, 44, 296-305.

[71] L.A. Gaston, M. A. Locke, R.M. Zablotowicz, K. N. Reddy, Spatia variability of soil properties and weed populations in the Mississippi delta, Soil Sci. Soc. Am. J. 2001, 65, 449-459.

[72] S. J. Writh, Regional-scale analysis of soil microbial biomass and soil basal $\mathrm{CO}_{2}$-respiration in northeastern Germany, in Sustaining the Global Farm (Ed: D. E. Scott, R. H. Mohtar, G. C. Steinhardt), Selected Papers from the $10^{\text {th }}$ International Soil Conservation Organization Meeting held May 24-29, 1999 at Purdue University and the USDA-ARS National Soil Erosion Research Laboratory 2001, 486-493.

[73] B. Beliaeff, M. L. Cochard, Applying geostatistics to identification of spatial patterns of fecal contamination in a mussel farming area (Harvre de la Vanlée, France), Water Res. 1995, 29 (6), 1541-1548.

[74] G. P. Robertson, K. M. Klingensmith, M. J. Klug, E. A. Paul, J. R. Crum Soil resources: Microbial activity, and primary production across and agricultural ecosystem, Ecol. Applic. 1997, 7 (1), 158-170.

[75] D. K. Oline, M.C. Grant, Scaling patterns of biomass and soil properties: An empirical analysis, Landscape Ecol. 2002, 17, 13-26.

[76] C. Gruden, Q.S. Fu, A. L. Barkovskii, I. D. Albrecht, M. M. Lynam, P. Adriaens, Dechlorination of dioxins in sediments: Catalysts, mechanisms, and implications for remedial strategies and dioxin cycling, in $D e$ halogenation: Microbial Processes and Environmental Applications (Ed M. M. Häggblom, I. D. Bossert), John Wiley \& Sons, New York, USA 2003, 347-373

[77] N. Barabás, Quantitative evaluation of dechlorination signatures in contaminated sediments using modified polytopic vector analysis with uncertainty assessment, $P h D$ Thesis, University of Michigan, USA 2003. 